\section{(2) OPEN ACCESS}

\title{
The temporary ban on tobacco sales in South Africa: lessons for endgame strategies
}

\author{
Samantha Filby 두, Kirsten van der Zee, Corné van Walbeek
}

Research Unit on the Economics of Excisable Products, University of Cape Town School of Economics, Rondebosch, South Africa

\section{Correspondence to}

Samantha Filby, Research Unit on the Economics of Excisable Products, University of Cape Town School of Economics, Rondebosch 7701, South Africa; samantha.filby@uct.ac.za

Received 7 September 2020 Revised 25 November 2020 Accepted 11 December 2020

\section{ABSTRACT}

Background The endgame literature recommends that, for a tobacco sales ban to be successful, several demandside preconditions (eg, low prevalence and effective cessation support) should be in place. The South African Government imposed a ban on the sale of all tobacco and vaping products between 27 March and 17 August 2020, as part of the COVID-19 lockdown.

Objectives To assess how cigarette smokers responded to the sales ban, to evaluate how the ban impacted the cigarette market in South Africa and to use the South African experience to inform endgame planning. Methods Regular preban cigarette smokers completed an online questionnaire from 4 to 19 June $2020(n=23$ 631), in which they reported on their prelockdown cigarette smoking patterns, quitting behaviour (if relevant) and smoking behaviour during the ban. Results About $9 \%$ of prelockdown smokers in the sample successfully quit smoking. $93 \%$ of continuing smokers purchased cigarettes despite the sales ban. The average price of cigarettes increased by $250 \%$ relative to prelockdown prices. Most respondents purchased cigarettes through informal channels.

Conclusions The demand-side preconditions for an effective sales ban were not in place in South Africa, making a sales ban inappropriate. The South African experience suggests that supply-side factors are also important in ensuring the success of a sales ban. These are: (1) the illicit market must be under control before implementing a sales ban; and (2) an effective sales ban needs to be synchronised with a ban on the manufacture, transport and distribution of cigarettes.

\section{INTRODUCTION}

On 15 March 2020, South African President Cyril Ramaphosa declared a National State of Disaster in response to the COVID-19 pandemic. Eight days later, he announced a nationwide lockdown, starting on 27 March 2020. On 25 March, 2 days before the lockdown began, the Government declared that all tobacco and vaping products were considered nonessential, and therefore prohibited the sale of these products during the lockdown. ${ }^{1}$ The Government's reason for the ban stemmed from concerns about the risk of COVID-19 transmission from people sharing cigarettes/tobacco pipes, and the presumption that smokers are more likely to develop serious illnesses when infected with COVID-19, thereby overwhelming the health sector. ${ }^{1}$

On 23 April, President Ramaphosa announced a phased approach to ending the lockdown. ${ }^{2}$ The president indicated that the lockdown conditions would be eased slightly on 1 May, as the country moved from lockdown level 5 to level 4 . The president announced that the tobacco and vaping product sales ban would be lifted on 1 May, but this decision was reversed a few days later. ${ }^{3}$

In response to Government's decision to continue the prohibition on tobacco sales, the representative body of most domestic tobacco producers, the Fair-Trade Independent Tobacco Association (FITA), filed a lawsuit against the South African Government in the Pretoria High Court in early May. ${ }^{4}$ FITA's case-arguing that cigarettes are addictive and should thus be regarded as essential products-was rejected by the court. The case did, however, result in the reinterpretation of the level 4 amendment to the lockdown regulations, which permitted tobacco manufacturers to produce for the export market. ${ }^{4}$ In early June, after the country moved to lockdown level 3 and the tobacco sales ban was again not lifted, British American Tobacco (BAT) filed a lawsuit in the Western Cape High Court on the grounds that the ban was 'unconstitutional'. The case was heard in early August. Before the verdict could be announced, the president announced that the tobacco sales ban would be lifted as the country moved from lockdown level 3 to level 2 on 17 August $2020 .^{6}$

Botswana and India are the only other countries to have banned tobacco sales as part of their COVID-19 response. The sales bans in Botswana and India were lifted after 12 weeks ${ }^{7}$ and 6 weeks, ${ }^{8}$ respectively. In South Africa, the sales ban lasted 5 months. The only other country that has banned the sale of tobacco (unrelated to COVID-19) is Bhutan, which has had a ban since 2004, although they have allowed small quantities of tobacco to be imported for personal consumption. ${ }^{9}$ South Africa's experience during lockdown thus provides a rare case study of a tobacco sales ban, although temporary, at a national level.

Since 2009, an 'endgame strategy' literature, much of which has been published in Tobacco Control, has developed. ${ }^{10-13}$ While the options for such a strategy are still being debated, a ban on the sale of cigarettes features prominently in this literature..$^{14} 15$ The sales ban literature, acknowledging that a sales ban is a radical and unprecedented step, sets out preconditions for it to be successful. For example, smoking prevalence should be low (typically less than 10\%), smokers should be encouraged to quit smoking and supported in their attempts and there should be a long lead-in time before the ban becomes effective. ${ }^{15}$

Opponents of a sales ban argue that it would encourage illicit trade. ${ }^{14}$ Proponents of a sales ban counter these objections on the grounds that the threat of illicit trade and the size of the illicit market are often exaggerated. ${ }^{15}$ In addition, they 
acknowledge that while some illicit sales are likely to occur, the public health consequences of an increase in the size of the illicit market are likely to be less detrimental than the status quo. ${ }^{15}$

In this paper, we analyse a novel survey of cigarette smokers during a 5-month cigarette sales ban, to assess how the ban impacted smoking behaviour. We use the South African experience to inform endgame planning.

\section{METHODOLOGY}

A self-administered online survey was conducted among smokers between 4 and 19 June 2020. The survey was completed by people aged 18 and older who were regular cigarette smokers (at least one cigarette per day) the week before the cigarette sales ban was announced. Other tobacco products and electronic cigarettes were not covered in the survey because they make up a minuscule proportion of the nicotine market.

The questionnaire included questions about smoking behaviour before and during the sales ban period, information on stocking up before the lockdown, quitting behaviour during the lockdown and demographic information. Respondents also reported their perceptions on various lockdown policies. The questionnaire and data are available at

https://www.datafirst.uct.ac.za/dataportal/index.php/catalog

The survey was developed and hosted on the SurveyMonkey website. We used Twitter and a petition site (www.change.org) to publicise the survey. It was also hosted on Moya Messenger, a data-free/airtime-free instant messaging service, and costs were covered as part of the survey set-up. Using the data-free platform allowed us to target lower income respondents. Participation was encouraged by offering respondents the opportunity to win a prize. Only one response was allowed per device.

In total, 34321 respondents started the survey. These responses were cleaned (removal of under 18s, non-smokers, incomplete responses, outliers, and so on), leaving 23631 analysable observations. There were 204 respondents who did not complete the survey, but provided sufficient information to be included in the quitting analysis. For all other analyses, we use only the respondents who completed the survey.

We noted several price outliers which indicated that errors had been made in response to the price questions. Where obvious errors were observed, a set of correction rules was followed. A detailed description of these rules is outlined in the report Smoking and quitting behaviour in lockdown South Africa: results from a second survey.

Because smoking and quitting behaviours in South Africa have distinct ethnic and gender dimensions, our results are disaggregated by ethnicity and gender. Under apartheid, people were classified into four main groups, namely Black/African (henceforth 'African'), Coloured, Indian and White. In South Africa, 'Coloured' is a non-derogatory term that refers to people with a mixed (typically San, Khoi, White, African and Malaysian) ethnic heritage. Socioeconomic differences in South Africa still have very pronounced ethnic dimensions.

\section{RESULTS}

The sample consists of $38 \%$ males and $61 \%$ females (table 1). Whites represent around $57 \%$ of the sample, followed by Coloured (18\%), Africans (13\%) and Indians (5\%). Most respondents have either completed high school or have a tertiary qualification. The average level of education of respondents is substantially higher than that of the overall South African population.

\begin{tabular}{lcc}
\hline Table 1 & Descriptive statistics & \\
\hline \multicolumn{1}{l}{ Proportion of sample } & Frequency \\
\hline Gender & & 23631 \\
\hline Female & 60.7 & 14332 \\
\hline Male & 37.5 & 8851 \\
\hline Prefer not to answer & 1.9 & 448 \\
\hline Ethnic group & & 23631 \\
\hline African & 13.3 & 3151 \\
\hline Asian/Indian & 4.7 & 1098 \\
\hline Coloured & 17.8 & 4203 \\
\hline White & 56.5 & 13348 \\
\hline Other and Prefer not to answer & 7.8 & 1831 \\
\hline Education & & 22287 \\
\hline Less than secondary school & 11.7 & 2614 \\
\hline Secondary school completed & 37.4 & 8328 \\
\hline College and undergraduate education & 36.1 & 8053 \\
\hline Postgraduate education & 14.8 & 3292 \\
\hline
\end{tabular}

Numbers in bold represent totals for each category.

Table 2 shows that $27 \%$ of smokers in the sample attempted to quit smoking cigarettes during lockdown. Of these, 33\% were successful. Thus, approximately $9 \%(27 \% \times 33 \%)$ of all respondents reported quitting successfully, following the introduction of the sales ban. Except for Africans, males of all ethnic groups have reportedly been more successful at quitting than females (table 2). There are substantial ethnic differences in quitting attempts and success, with Africans being more likely to quit than the other ethnic groups. More than $70 \%$ of successful quitters intended to remain abstinent after the sales ban.

More than $70 \%$ of respondents who quit did so during the first 6 weeks of lockdown (not shown in the tables). Relatively few respondents quit in the subsequent 6 weeks. The single most important reason for attempting to quit was that cigarettes became too expensive during lockdown (57\%), followed by not being able to find cigarettes (14\%). Only $11 \%$ of respondents attempted to quit because they felt motivated by the ban per se. Respondents who successfully quit during lockdown smoked an average of 8 cigarettes per day before lockdown, substantially fewer than the 16 cigarettes smoked per day by respondents who said they did not quit.

About $93 \%$ of the respondents who continued smoking during lockdown indicated that they purchased cigarettes during the lockdown.

The retail market for cigarettes changed substantially before and during the lockdown (figure 1). Before the ban, $70 \%$ of respondents purchased cigarettes through formal channels, namely retail outlets (53\%), petrol stations (7\%), tobacco shops (5\%) and wholesalers (5\%). During lockdown, however, purchases from formal outlets were negligible. The most important outlet types in our sample during lockdown were 'through friends/family' (27\%), spaza shops (small, informal convenience retail outlets) (25\%) and street vendors (11\%).

Table 3 shows that the average reported per-cigarette price increased from R1.63 (roughly US\$0.10) before ban to R5.69 (roughly US\$0.35) in June 2020, an increase of nearly $250 \%$. The dispersion of prices also changed considerably. Before the ban, the SD in the price of individual brands was R0.55 per stick, but this increased to roughly R2.70 during the ban.

The average price of non-multinational corporation (nonMNC) cigarettes (R1.00) was substantially lower than the average price of MNC cigarettes (R1.90) before the ban. During 
Table 2 Quitting behaviour during the lockdown

\begin{tabular}{|c|c|c|c|c|c|}
\hline & $\mathrm{n}$ & $\begin{array}{l}\text { Attempt to quit } \\
(\%)\end{array}$ & $\begin{array}{l}\text { Successful quitter given } \\
\text { quit attempt }(\%)\end{array}$ & $\begin{array}{l}\text { Successful quitters from } \\
\text { all pre-LD smokers (\%) }\end{array}$ & $\begin{array}{l}\text { Intent-to-stay non-smokers, } \\
\text { given successful quitting ( } \%)\end{array}$ \\
\hline & 1 & 2 & 3 & 4 & 5 \\
\hline Males & 8342 & 32.9 & 40.8 & 13.5 & 73.8 \\
\hline African & 2165 & 62.4 & 56.7 & 35.5 & 79.8 \\
\hline Coloured & 1300 & 35.4 & 34.8 & 12.3 & 72.5 \\
\hline Indian & 589 & 28.9 & 22.4 & 6.5 & 65.8 \\
\hline White & 4288 & 17.9 & 20.6 & 3.7 & 47.5 \\
\hline Females & 13373 & 23.7 & 27.6 & 6.6 & 69.4 \\
\hline African & 945 & 68.1 & 69.3 & 47.5 & 79.4 \\
\hline Coloured & 2880 & 30.9 & 26.8 & 8.4 & 68.3 \\
\hline Indian & 490 & 24.3 & 25.2 & 6.1 & 60.0 \\
\hline White & 9058 & 16.8 & 10.6 & 1.8 & 45.1 \\
\hline Ethnicity and/or gender undisclosed & 2126 & 25.3 & 27.7 & 7.0 & 59.1 \\
\hline Total & 23835 & 27.1 & 33.2 & 9.0 & 70.9 \\
\hline
\end{tabular}

1. The number of observations ( $\mathrm{n}$ ) refers to the respondents who have answered the first question 'Have you attempted to quit smoking since the sale on cigarettes was banned due to lockdown (since 27 March)?'.

2. 'Attempt to quit' is an indicator for whether or not the respondent had attempted to quit during the lockdown (asked of all respondents).

3. 'Successful quitter given quit attempt' is an indicator for whether the respondent has been successful in the attempt to quit (asked only of those who had attempted to quit).

4. 'Successful quitters from all pre-LD smokers' represents the number of individuals who had successfully quit, as a proportion of all respondents (including both those who had and had not attempted to quit).

5. 'Intent-to-stay non-smokers, given successful quitting' is an indicator for whether successful quitters intended to start smoking again or not, after the cigarette sales ban (asked only of successful quitters).

LD, lockdown.

the ban, the average price of non-MNC brands increased to R5.57 (a $457 \%$ increase) while the average price of MNC brands rose to R6.30 per cigarette (a 232\% increase).

Table 4 indicates the shares of the most prevalent cigarette manufacturers before and during the sales ban. For this analysis, we weight each response by the reported number of cigarettes smoked daily by him/her in each time period.

The distribution of producers in the sample (derived from reported brands) changed dramatically. Before the ban, the top four producers produced $87 \%$ of the cigarettes consumed by respondents (table 4). After the sales ban, this same market share $(87 \%)$ is made up of eight producers, indicating that the market has become substantially less concentrated during the sales ban.

MNCs (ie, BAT, Philip Morris International and Japan Tobacco International) dominated the market prior to the ban, but there were no MNCs in the top five manufacturers in June 2020. In fact, all three MNCs lost substantial market share among our sample during the ban while the market shares of the non-MNCs

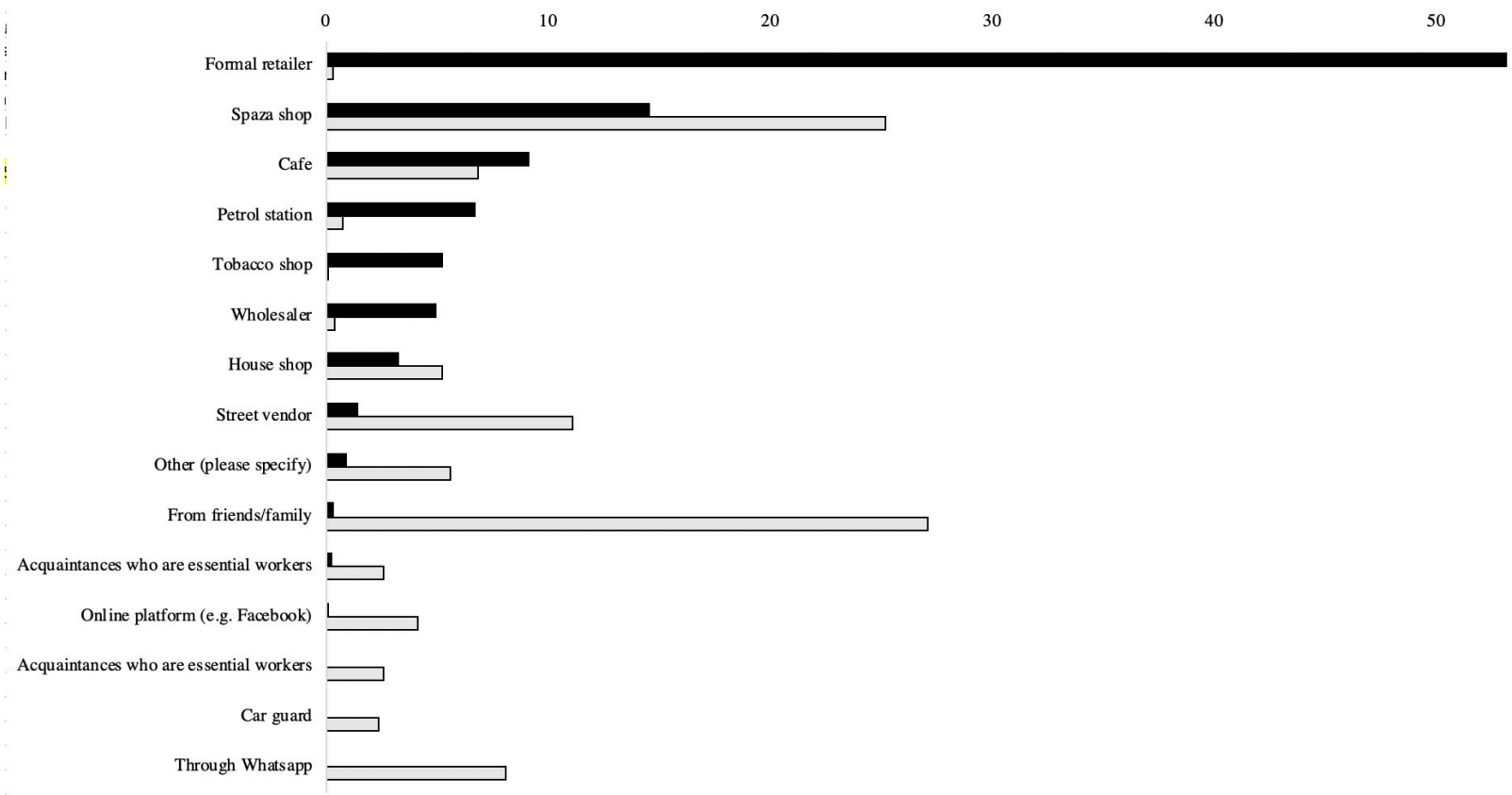

-Before lockdown $\quad$ DDuring lockdown

Figure 1 Distribution of outlets where smokers purchased cigarettes before and after the cigarette sales ban (\%). n=21 150 before lockdown and $\mathrm{n}=19962$ during lockdown. 
Table 3 Per-stick cigarette prices (in rand) before and during the sales ban, by manufacturer

\begin{tabular}{|c|c|c|c|c|c|c|c|c|c|c|c|}
\hline \multirow[b]{2}{*}{ Manufacturer } & \multirow[b]{2}{*}{ Classification } & \multicolumn{4}{|c|}{ Before lockdown } & \multicolumn{4}{|c|}{ Lockdown } & \multicolumn{2}{|c|}{$\%$ change } \\
\hline & & Mean & Median & SD & $\mathrm{n}$ & Mean & Median & SD & n & Mean & Median \\
\hline British American Tobacco & MNC & 1.81 & 1.75 & 0.41 & 9846 & 6.17 & 6.00 & 2.95 & 1814 & 240.7 & 242.9 \\
\hline Japan Tobacco International & MNC & 1.79 & 1.75 & 0.37 & 2990 & 6.02 & 5.50 & 2.72 & 780 & 237.3 & 214.3 \\
\hline Philip Morris International & MNC & 1.92 & 1.90 & 0.35 & 2538 & 7.09 & 7.00 & 2.99 & 982 & 269.8 & 268.4 \\
\hline Afroberg Tobacco & Non-MNC (FITA) & 0.71 & 0.55 & 0.54 & 73 & 4.34 & 3.50 & 2.20 & 614 & 510.5 & 536.4 \\
\hline Best Tobacco & Non-MNC (FITA) & 1.01 & 1.00 & 0.50 & 298 & 7.26 & 7.50 & 2.76 & 2537 & 621.6 & 650.0 \\
\hline Carnilinx & Non-MNC (FITA) & 0.93 & 0.80 & 0.39 & 921 & 6.30 & 6.00 & 2.62 & 2859 & 581.1 & 650.0 \\
\hline Folha & Non-MNC (FITA) & 0.98 & 0.75 & 0.65 & 21 & 4.12 & 3.25 & 1.89 & 75 & 321.7 & 333.3 \\
\hline Gold Leaf Tobacco & Non-MNC (FITA) & 1.06 & 1.00 & 0.48 & 2277 & 5.34 & 4.25 & 2.51 & 5154 & 401.8 & 325.0 \\
\hline Protobac & Non-MNC (FITA) & 0.91 & 0.75 & 0.33 & 55 & 7.39 & 7.00 & 4.06 & 76 & 711.2 & 833.3 \\
\hline Amalgamated Tobacco & Non-MNC & 0.80 & 0.75 & 0.44 & 298 & 4.46 & 3.75 & 2.02 & 1707 & 457.4 & 400.0 \\
\hline Mastermind Tobacco & Non-MNC & 0.30 & 0.30 & - & 1 & 3.42 & 3.25 & 0.90 & 52 & 1040.4 & 983.3 \\
\hline Olomide & Non-MNC & 1.09 & 0.75 & 0.91 & 47 & 3.97 & 3.50 & 1.85 & 373 & 263.6 & 366.7 \\
\hline Pacific Cigarette & Non-MNC & 0.90 & 0.75 & 0.52 & 367 & 4.44 & 3.75 & 1.96 & 1489 & 394.1 & 400.0 \\
\hline Smokey Treats & Non-MNC & 2.05 & 2.13 & 0.33 & 16 & 4.25 & 3.75 & 1.94 & 4 & 107.3 & 76.5 \\
\hline Other & & 0.91 & 0.75 & 0.53 & 174 & 4.93 & 4.00 & 2.62 & 1294 & 452.6 & 433.3 \\
\hline Overall & & 1.63 & 1.65 & 0.55 & 19922 & 5.69 & 5.00 & 2.73 & 19810 & 248 & 203 \\
\hline
\end{tabular}

All prices (irrespective of the packaging type in which the respondent reported) are converted to a per-stick price. Manufacturers are determined according to the brand reported by the respondent.

FITA, member of the Fair-Trade Independent Tobacco Association at the time of the survey.; MNC, multinational corporation.

increased. Before the lockdown, 75\% of respondents smoked brands produced by MNCs, which decreased to $17 \%$ when the survey was conducted in June 2020.

\section{DISCUSSION}

The intention of the tobacco sales ban was to reduce smoking prevalence. Nine per cent of respondents quit smoking. Most of these quitters $(70 \%)$ indicated that they wished to remain abstinent after the ban. The positive public health consequences of the sales ban should be weighed up against the reality that most

Table 4 Individual manufacturers' share of cigarettes bought by survey respondents

\begin{tabular}{|c|c|c|c|}
\hline Manufacturer & Classification & $\begin{array}{l}\text { Prelockdown } \\
\text { proportion }\end{array}$ & $\begin{array}{l}\text { During lockdown } \\
\text { proportion (June } \\
2020 \text { ) }\end{array}$ \\
\hline British American Tobacco & MNC & 48.0 & 8.7 \\
\hline $\begin{array}{l}\text { Japan Tobacco } \\
\text { International }\end{array}$ & MNC & 15.3 & 4.1 \\
\hline Gold Leaf Tobacco & Non-MNC (FITA) & 12.2 & 26.3 \\
\hline Philip Morris International & MNC & 11.5 & 4.4 \\
\hline Carnilinx & Non-MNC (FITA) & 5.5 & 14.3 \\
\hline Pacific Cigarette & Non-MNC & 1.9 & 7.9 \\
\hline Amalgamated Tobacco & Non-MNC & 1.9 & 9.6 \\
\hline Best Tobacco & Non-MNC (FITA) & 1.5 & 10.7 \\
\hline Afroberg Tobacco & Non-MNC (FITA) & 0.5 & 3.4 \\
\hline Protobac & Non-MNC (FITA) & 0.4 & 0.4 \\
\hline Olomide & Non-MNC & 0.2 & 2.2 \\
\hline Folha & Non-MNC (FITA) & 0.1 & 0.4 \\
\hline Smokey Treats & Non-MNC & 0.1 & 0.0 \\
\hline Mastermind Tobacco & Non-MNC & 0.0 & 0.4 \\
\hline Other & & 1.1 & 7.3 \\
\hline Total & & 100 & 100 \\
\hline
\end{tabular}

All individual responses are weighted by their declared consumption. The observations, weighted by consumption, for each category are $n=345992$ (before ban) and $n=242541$ (during ban).

FITA, member of the Fair-Trade Independent Tobacco Association at the time of the survey; MNC, multinational corporation. continuing smokers were able to access cigarettes on the illicit market.

Even before the sales ban, the illicit market was booming. ${ }^{16} 17$ We believe that creating a situation where manufacturers/traders operated exclusively illicitly for an extended period of time gave them an opportunity to develop new and creative illicit distribution channels, making it likely that these distribution channels will be hard to eradicate after the ban.

Besides this, the structure of the South African cigarette market changed dramatically during the ban, as the hold of the MNCs weakened and the local manufacturers increased their share of the market. Economic theory suggests that the changing market structure could result in lower average cigarette prices as companies compete for market share, with detrimental public health consequences. ${ }^{18}$

Furthermore, the shifting power balance away from the MNCs towards the smaller, less sophisticated local/regional producers is not likely to improve government's scope for furthering the tobacco control agenda in South Africa. Despite that MNCs throughout the world have a long record of interfering with government and influencing national tobacco control narratives, ${ }^{19}$ we believe that this is not the case in South Africa anymore. In recent years, the large role played by the multinationals in undermining South African institutions, like the South African Revenue Service (SARS), has been publicly exposed. ${ }^{20-22}$ This has diminished their credibility and influence in the policy space, even before the lockdown.

Ultimately, whether one perceives the effect of the ban as positive or negative depends on the relative weight that one places on the number of successful quitters versus the increase in illicit trade. While we do not assess the impact of the sales ban on the spread of COVID-19, or the public health burden during the crisis, we believe that our results can contribute to the endgame literature. We make two contributions with this paper.

First, we argue that South Africa should not be used as a case study either to support or refute the idea of using a sales ban as part of an effective endgame strategy, because the preconditions required for a successful sales ban were not in place. Second, given the evidence that the majority of smokers continued to purchase cigarettes despite the ban, the South African experience 
illustrates the importance of taking the supply side (especially controls on illicit trade) into consideration.

As theorised by Smith and Malone, smoking prevalence should be low-less than $10 \%$-by the time a sales ban is instituted. ${ }^{15}$ South Africa's preban smoking prevalence of around $20 \%{ }^{23}$ is therefore too high for a comprehensive sales ban to have been successful.

Current endgame literature also argues that a sales ban should be announced well in advance of implementation, giving smokers time to quit. ${ }^{13}$ Cessation medication and counselling services should be made available well before the ban is implemented. ${ }^{13}$ In South Africa, smokers had 2 days warning. Other than preexisting telephonic quit lines, there was no additional cessation support given to smokers during the ban.

The current preconditions for a successful sales ban, discussed in the endgame literature, focus primarily on the demand side. Because they assume that smoking prevalence will be low by the time a sales ban is implemented, proponents of a sales ban pay little attention to the supply side beyond acknowledging that any policy that restricts supply may lead to increased illicit trade. ${ }^{13}$ Even so, increases in illicit trade are seen as a small price to pay to abolish the sale of a lethal product, especially when the precondition of low prevalence is met. ${ }^{15}$

Rather than addressing the threat of illicit trade by assuming that prevalence will be low at the time a sales ban is instituted, endgame strategists ought to address the issue directly by adding supply-side factors to the existing list of preconditions for a successful sales ban.

The illicit cigarette market should be under control before a ban is implemented. In South Africa, illicit cigarettes comprised around a third of all cigarette sales before the ban came into effect, ${ }^{1617}$ and distribution channels for illicit cigarettes were therefore well established. It could have been predicted that the existing illicit market would continue to operate, and in fact flourish, during the lockdown if no significant interventions were implemented. The sales ban substantially increased the presence of cigarette brands that, before ban, were mostly sold at prices indicating that they were illicit (tax unpaid). Companies that, before lockdown, had been selling cigarettes through informal and often illicit distribution channels had a significant advantage over companies that sold their cigarettes mostly through formal channels.

South Africa's capacity to contain the illicit cigarette trade has been under strain in recent years. The then commissioner of SARS abolished the specialised units aimed at fighting illicit trade in 2015 and 2016 on spurious allegations of wrongdoing. ${ }^{24}$ This enforcement vacuum allowed the illicit market to thrive. The new commissioner created an illicit economy unit in 2018 but it is yet to prove its effectiveness at curbing the illicit cigarette trade. Attempts to introduce a track-and-trace system have collapsed after numerous attempts. South Africa has not ratified the Protocol to Eliminate Illicit Trade in Tobacco Products. ${ }^{25}$ Within an environment of weak oversight, the tobacco industry has extensive room to manoeuvre and can do as it pleases.

The South African experience also suggests that an effective sales ban should be synchronised with a ban on the manufacture, transport and distribution of cigarettes, and strong monitoring of these sectors. In South Africa, an untenable situation arose when cigarette sales were forbidden but manufacturers could continue to produce cigarettes, ostensibly for export. The incentive to divert a substantial proportion of those cigarettes to the domestic market, particularly in an environment with poor illicit trade enforcement, would have been hard to resist.

\section{LIMITATIONS}

We restrict the focus of this paper to assessing only how effective the sales ban was at limiting the sale of cigarettes, and where sales continued, the changes within the lockdown cigarette market. We do not assess how the ban impacted the spread of COVID-19, or whether it reduced the tobacco-related burden on the public health system, as these assessments are best left to medical and public health experts.

The survey had no specific sampling frame. Because it was an online survey, poorer subgroups of the population were under-represented. Nationally representative surveys in South Africa show that poorer smokers tend to smoke fewer cigarettes per day and are more likely to purchase single sticks than richer smokers. ${ }^{2326}$ Compared with the smoking population in nationally representative surveys, our survey substantially oversampled females, Whites and the Gauteng and Western Cape provinces, and undersampled males, Africans and the other seven provinces. We considered weighting the data by ethnic group, gender and province to account for this oversampling and undersampling, but because the survey respondents at the bottom end of socioeconomic spectrum do not portray a random draw of smokers from those groups, the data set is not a good candidate for weighting. Weighting may introduce biases, as opposed to correcting for them. Given this drawback, we are unable to make inferences about South Africa's smoking population, but we can comment on the behaviour of the sample.

We advertised the survey to people who smoked at least one cigarette per day in the week before the lockdown. We explicitly asked people who quit smoking during the lockdown to complete the questionnaire. However, it is possible that people who quit during the lockdown may be under-represented in the survey because they felt that the questionnaire was not relevant to them. It is also possible that some people who were successful quitters at the time of the study may relapse in subsequent weeks and months, which would make them smokers again. These two forces work against each other, and one cannot know which effect dominates.

Our results do not capture the proportion of smokers who may have substituted to other tobacco and/or nicotine products. To the extent that there was substitution to other tobacco products, the public health benefit reported by respondents who have quit cigarettes may be overstated.

There may also be measurement error in so far as individuals did not answer truthfully about whether they were able to purchase cigarettes for fear of being caught, or the number of cigarettes they smoke, because there may be stigmas associated with smoking among specific demographic and cultural groups. ${ }^{27-29}$ We may also encounter biases deriving from the fact that smokers who were motivated to respond to and complete the survey may have been those with stronger opinions about the ban, or who were most affected by the ban, rather than the average smoker.

From the start, it was clear that the sales ban would be temporary. Instead of quitting, many smokers may have decided to circumvent the ban by buying expensive illicit cigarettes for a limited period. The behavioural response of smokers is likely to have been different, had the ban been announced well in advance, or a permanent measure.

\section{CONCLUSION}

In an attempt to reduce the negative health impact of COVID-19, South Africa implemented a sales ban on tobacco products. While the original intention of the ban was to reduce smoking prevalence, only a minority of respondents to our online survey managed to quit 
smoking, while the vast majority of respondents continued to buy cigarettes, despite the ban on tobacco sales.

The demand-side preconditions for an effective sales ban specified in the endgame literature were not in place in South Africa. Smoking prevalence was too high at the outset, there was insufficient cessation support and smokers did not have time to prepare for the ban. South Africa was therefore an inappropriate candidate for the implementation of a sales ban. It is thus incorrect to use the South African experience as evidence in favour, or against, the use of a sales ban as part of an endgame strategy.

Whereas the current thinking on endgame strategies focuses on demand-side preconditions that should be in place if a sales ban is to be successful, the South African experience indicates that supplyside factors are also important. We therefore propose two additional preconditions that need to be in place if sales bans are to work: (1) the illicit market needs to be under control before implementing a ban; and (2) a sales ban must be synchronised with a ban on the manufacture, transport and distribution of cigarettes, as well as

\section{What this paper adds}

What is already known on this subject

- Endgame strategies seek to ultimately abolish tobacco use.

- One such endgame strategy is to prohibit tobacco sales. In 2004, Bhutan became the first, and so far, only, country to implement a ban on the sale, production and distribution of tobacco products.

- The theoretical literature on using a tobacco sales ban as part of an endgame strategy recommends that the strategy be implemented in low-prevalence communities, that the ban be announced well in advance of implementation and that cessation support be made available to help people quit smoking.

- Opponents of a sales prohibition argue that it will lead to increased illicit trade.

What important gaps in knowledge exist on this topic

- No study has used survey data to provide empirical evidence of the impact of an outright ban of commercial tobacco product sales.

- No study uses a case study of a tobacco sales ban to inform recommendations on the preconditions that need to be in place for a ban on tobacco sales to be successful.

\section{What this paper adds}

- Using South Africa as a case study, we show the impact of a temporary sales ban on smoking behaviour and the market for cigarettes, for a sample of smokers.

- South Africa's experience shows why pre-existing, demandside conditions need to be met before implementing a sales ban.

- Whereas the current thinking on tobacco sales bans focuses on demand-side preconditions that need to be in place for a sales ban to be successful, the South African experience indicates that supply-side factors, particularly the control of illicit trade and tobacco supply chains, are also important in ensuring the success of a sales ban.

- Our results suggest that, in countries where smoking prevalence is still high, and other preconditions for a sales ban are not in place, especially when there are high levels of (preban) illicit trade, a sales ban may greatly increase the illicit trade in cigarettes. strong monitoring of these sectors to ensure that production and distribution cease.

Correction notice This article has been corrected since it first published. The provenance and peer review statement has been included.

Acknowledgements We are grateful to Ms Nicole Vellios, Ms Elizabeth Baldwin and three anonymous reviewers for their comments on earlier versions of this paper.

Contributors CvW conceptualised the initial study. KvdZ and CvW designed the questionnaire. SF managed the survey coordination. SF and KvdZ conducted the data analysis. SF led the writing of the manuscript and all authors contributed to writing of the manuscript. All authors have first author status.

Funding This study was funded by the Bill \& Melinda Gates Foundation through the African Capacity Building Foundation (grant number 334).

Competing interests None declared.

Patient consent for publication Not required.

Ethics approval Ethics approval was granted by the University of Cape Town's Commerce Faculty Ethics in Research Committee (ref: REC 2020/04/024).

Provenance and peer review Not commissioned; externally peer reviewed.

Data availability statement Data are available in a public, open access repository. Data are available on the DataFirst Open data portal: https://www. datafirst.uct.ac.za/dataportal/index.php/catalog.

Open access This is an open access article distributed in accordance with the Creative Commons Attribution Non Commercial (CC BY-NC 4.0) license, which permits others to distribute, remix, adapt, build upon this work non-commercially, and license their derivative works on different terms, provided the original work is properly cited, appropriate credit is given, any changes made indicated, and the use is non-commercial. See: http://creativecommons.org/licenses/by-nc/4.0/.

\section{ORCID iD}

Samantha Filby http://orcid.org/0000-0001-6371-6522

\section{REFERENCES}

1 Gerber J. We understood the reasons and we agree, 'says parliamentary health Committee chair. News24, 2020.

2 Ramaphosa C. President Cyril Ramaphosa: South Africa's response to Coronavirus COVID-19 pandemic, 2020.

3 Manyathela C. Ramaphosa admits he should have explained govt's u-turn on cigarette sales. EyeWitness News, 2020.

4 Ndaba B. Legal showdown between government and FitA put on hold for now, 2020.

5 Palm K. British American Tobacco's cigarette sale ban to be heard in court. EyeWitness News, 2020.

6 Ramaphosa C. Statement by president Cyril Ramaphosa on progress in the National effort to contain the Covid-19 pandemic. Union Buildings, Tshwane, South Africa, 2020.

7 Presidential Task Force. Presidential (COVID-19) Task force Bulletin. government of Botswana, 2020.

8 Economic Times India. Lockdown extension: liquor, cigarette sale is now allowed but conditions apply. Economic Times India, 2020.

9 Givel M. Tobacco Policymaking and administration in Bhutan from 1991 to 2009. Int Publ Admin 2011:34:775-82.

10 Malone RE. Imagining things otherwise: new endgame ideas for tobacco control. Tob Control 2010;19:349-50.

11 Warner KE. An endgame for tobacco? Tob Control 2013;22:i3-5.

12 Thomson G, Edwards R, Wilson N, et al. What are the elements of the tobacco endgame? Tob Control 2012;21:293-5.

13 McDaniel PA, Smith EA, Malone RE. The tobacco endgame: a qualitative review and synthesis. Tob Control 2016;25:594-604.

14 Hanauer P. The case against tobacco prohibition. Tob Control 2009;18:3-4.

15 Smith EA, Malone RE. An argument for phasing out sales of cigarettes. Tob Control 2020;29:tobaccocontrol-2019-055079.

16 Vellios N, van Walbeek C, Ross H. Illicit cigarette trade in South Africa: 2002-2017. Tob Control 2019;29.

17 van der Zee K, van Walbeek C, Magadla S. Illicit/cheap cigarettes in South Africa. Trends Organ Crime 2020;23:242-62.

18 International Agency for Research on Cancer. Effectiveness of Tax and price policies for tobacco control. IARC handbooks of cancer prevention, tobacco control vol 14 Lyon, France: international agency for research on cancer, 2011.

19 Gilmore AB, Fooks G, Drope J, et al. Exposing and addressing tobacco industry conduct in low-income and middle-income countries. Lancet 2015;385:1029-43.

20 Judge Nugent R. Commission of inquiry into Tax administration and governance by the South African revenue service, final report, 2019. Available: http://www. thepresidency.gov.za/ 
21 Snyckers T. Dirty tobacco: Spies, lies and Mega-Profits. Cape Town: Tafelberg, 2020.

22 van Loggerenberg J. Tobacco Wars: Inside the spy games and dirty tricks of southern Africa's cigarette trade. Cape Town: Tafelberg, 2019.

23 University of Cape Town SALDRU. National income dynamics study, wave, 2017: 5

24 Pauw J. President's keepers. Cape Town: NB Publishers, 2017.

25 United Nations Treaty Collection. Protocol to eliminate illicit trade in tobacco products, 2020.

26 South African Audience Research Foundation. South Africa - All Media and Products Survey, 2015.
27 Pérez-Stable EJ, Marín BV, Marín G, et al. Apparent underreporting of cigarette consumption among Mexican American smokers. Am J Public Health 1990;80:1057-61.

28 Roth MA, Aitsi-Selmi A, Wardle H, et al. Under-Reporting of tobacco use among Bangladeshi women in England. J Public Health 2009;31:326-34.

29 Dietz PM, Homa D, England LJ, et al. Estimates of nondisclosure of cigarette smoking among pregnant and nonpregnant women of reproductive age in the United States. Am J Epidemiol 2011;173:355-9. 